\title{
A LOW-COST SECOND GENERATION SINGLE CRYSTAL SUPERALLOY DD6
}

\author{
J. R. Li, Z. G. Zhong, D. Z. Tang, S. Z. Liu, P. Wei, P. Y. Wei, Z. T. Wu, D. Huang and M. Han \\ Beijing Institute of Aeronautical Materials \\ P. O. Box 81-1 \\ Beijing 100095, China
}

\begin{abstract}
A low-cost second generation single crystal (SC) superalloy, designated DD6, has been developed for aeroengine turbine blade applications. DD6 contains $2 \mathrm{wt}$. \% rhenium, which is about $2 / 3$ of that of the second generation single crystal superalloys such as PWA1484, CMSX 4 and René N5. The alloy system employs the relatively high additive refractory element (tungsten, molybdenum, tantalum, rhenium and niobium) content of about 19.5 wt. \%. A cost reduction of about $25 \%$ is expected for this alloy.
\end{abstract}

DD6 alloy has an approximate $40^{\circ} \mathrm{C}$ improvement of creep strength relative to the first generation single crystal superalloys such as DD3, a Chinese first generation single crystal alloy whose creep rupture properties are comparable with PWA1480 alloy. The tensile properties and creep rupture properties of the alloy are comparable to those of the second generation single crystal alloys such as SC180, René N5, CMSX-4 and PWA1484. Most notably, the alloy provides superior oxidation resistance and good hot corrosion resistance. The advantage shown in the creep rupture properties over DD3 also generally hold for fatigue properties.

DD6 also has good microstructure stability, heat treatment characteristics and environmental properties.

Casting trials have been conducted on DD6 involving a great number of bars and some complex shaped hollow turbine blades. These trials demonstrated that DD6 possesses excellent single crystal castability.

\section{Introduction}

First generation and second generation single crystal alloys have been widely used for advanced commercial and military aeroengines since the $1980^{\prime} \mathrm{s}^{[1-16]}$, and third generation single crystal alloys have recently been developed ${ }^{[17-21]}$. The second generation single crystal alloys provide an approximate $30^{\circ} \mathrm{C}$ improvement of creep strength relative to the first generation, while the third generation exhibit about $60^{\circ} \mathrm{C}$ improvement of creep strength in comparison to the first. Table 1 presents the compositions of first, second and third generation single crystal alloys, including DD6 and DD3. A main distinction of the chemical compositions of the first, second and third generation single crystal superalloys is thenium-free, 3 wt. \% Re and 6 wt. \% $\mathrm{Re}$, respectively ${ }^{[1-21]}$. The effects of $\operatorname{Re}$ on the mechanical properties of single crystal superalloys are very significant, especially in improving the creep rupture life. However, Re is a rare element and the price of $R e$ is very expensive. The aeroengine manufacturers all consider $R e$ as a strategic element. Therefore, the development of low-Re second generation single crystal alloy is important. The goals of the present research were as follows: 1) develop a low cost second generation single crystal alloy, using low Re; 2) maintain the mechanical properties of the alloy at levels equivalent to those of the second generation single crystal alloys, such as SC180, René N5, CMSX-4 and PWA1484; 3) design a alloy combining high strengths with good environmental properties, microstructural stability, heat treatment characteristics and castability.

A low-cost second generation single crystal alloy, designated DD6, has been developed by Beijing Institute of Aeronautical Materials for aeroengine blade applications. Based on the study of single crystal superalloys for many years, with the help of the computer aided design of alloy compositions, the contents of tungsten, molybdenum, tantalum, rhenium and aluminum were judiciously balanced with the predominating rhenium requirement. A large number of trials were carried out, and the composition for DD6 alloy has been determined. The alloy contains $2 \mathrm{wt}$. $\% \mathrm{Re}$, and the alloy system employs the relatively high additive refractory element ( $\mathrm{W}, \mathrm{Mo}, \mathrm{Ta}, \mathrm{Re}$ and $\mathrm{Nb}$ ) content of about 19.5 wt. \%; this in comparison to DD3 which is about 9.5 wt. \%. The Re content of DD6 alloy is about $2 / 3$ of that of other second generation single crystal alloys such as PWA1484, CMSX-4 and René N5. Thus a cost reduction of about $25 \%$ for this alloy is expected in China.

The microstructural stability at temperatures above $1000^{\circ} \mathrm{C}$ was a 
key concem during the development of DD6. TCP phase formation is typically observed in many single crystal superalloys, especially those containing $\mathrm{Re}$, although a small amount of TCP is not considered detrimental to creep rupture and other properties ${ }^{[19]}$. DD6 alloy exposed at $1093^{\circ} \mathrm{C}$ for 1000 hours shows no TCP phases formation and the microstructure of the alloy possesses good stability.

Table I Nominal compositions of three generations of single crystal supcralloys (wt. \%)



DD6 alloy has an approximate $40^{\circ} \mathrm{C}$ improved creep strength relative to the first generation single crystal superalloys such as DD3 alloy. The tensile properties and creep rupture properties of DD6 are comparable to those of the second generation single crystal superalloys such as SC180, René N5, CMSX-4 and PWA1484. The yield strength of DD6 alloy at $760^{\circ} \mathrm{C}$ is approximately $981 \mathrm{MPa}$. The creep rupture lives of DD6 at the conditions of $982^{\circ} \mathrm{C} / 248.2 \mathrm{MPa}, 1070^{\circ} \mathrm{C} / 160 \mathrm{MPa}$ and $1093^{\circ} \mathrm{C} / 124 \mathrm{MPa}$ are about 307 hours, 178 hours and 484 hours, respectively. Most notably, the alloy provides superior oxidation resistance and hot corrosion resistance ${ }^{[16]}$. The superior environmental properties of DD6 are attributable to its higher aluminum content and tantalum content, and the fact that it has optimum compositions. High cycle fatigue tests have been performed. The advantage shown in the creep rupture properties over DD3 generally hold for the fatigue properties.

Casting trials on DD6 alloy have been conducted involving a great number of slabs, bars and some complex shaped hollow turbine blades. These trials demonstrated that DD6 alloy is not prone to the formation of single crystal process defects such as freckles and slivers, and possesses excellent single crystal castability. The MCrAlX coating has been applied to DD6 alloy successfully.

\section{Alloy Design}

A common characteristic of the chemical compositions of the second generation single crystal superalloys widely used in the world is $3 \mathrm{wt} \% \mathrm{Re}^{[11-15]}$. Re has very important effects on improving the creep rupture life and it is the most expensive element in single crystal superalloys, so decreasing Re content will reduce alloy cost. The effects of Re on creep rupture life of a single crystal superalloy were studied in the period of DD6 development. It was found in the study that $\mathrm{Re}$ can greatly improve the creep rupture life, however the total level of refractory elements such as $\mathrm{W}, \mathrm{Mo}, \mathrm{Nb}$, Ta and $\mathrm{Re}$, also obviously affects the creep rupture life in single crystal superalloys ${ }^{[22]}$. Therefore, it is suggested that not only the Re content must be emphasized but also the total refractory element level in the alloy should be selected correctly. The Re content in DD6 alloy system was thereby designed to be about 2 wt. $\%$.

Generally, the second generation single crystal alloys contain 8-9 wt.\% of $\mathrm{W}+\mathrm{Re}$. On the basis of containing 2 wt. \% Re, relatively high $W+R e$ levels are employed to attain the high creep strength exhibited by DD6, particularly at elevated temperatures. Moreover, $\mathrm{W}$ and $\mathrm{Cr}$ tend to be involved in TCP phase formation. Utilizing high $\mathrm{W}$ content requires relatively low chromium alloying. 
Since tantalum is a more efficient hardener and has beneficial effect on single crystal castability in reducing alloy freckle formation, plus it positively influences environmental properties, a Ta level of about 7.5 wt. \% is employed in DD6 alloy system. Based on the mechanical properties, TCP and microstructural stability, environmental resistance and castability of the candidate alloys, the nominal composition of DD6 alloy was finally selected.

The results of phase calculations of DD6 alloy are listed in Table II. The values of the $\bar{M} d t$ and $\bar{N} v$ of DD6 are smaller than the critical values for alloy microstructure stability, respectively ${ }^{[23,24]}$. The $P$ value is a parameter which predicts the overall merit of the composition. The compositions with high $P$ values will have high strength in combination with stability, heat treatability and resistance to oxidation and corrosion. For an optimum alloy, the most useful composition currently known by the inventors, the $P$ value will be slightly in excess of $3940^{[12]}$. The various parameters in Table II show that DD6 alloy should has high strength, good microstructure stability, heat treatment characteristic and environmental properties.

Table II Results of the phase calculation of DD6 alloy ${ }^{[12,23,24]}$

\begin{tabular}{|c|c|c|c|c|}
\hline Design parameters & $\begin{array}{c}\bar{M} d t \\
\text { of alloy }\end{array}$ & $\begin{array}{c}\bar{N} v \\
\text { of } \gamma \text { matrix }\end{array}$ & $\begin{array}{c}P \\
\text { Value }\end{array}$ & $\begin{array}{c}\text { Misfit } \\
\text { of } \gamma^{\prime} \text { and } \gamma . \%\end{array}$ \\
\hline Calculated value & 0.969 & 1.869 & 3965 & -0.09 \\
\hline Critical value & 0.985 & 2.3 & 3940 & - \\
\hline
\end{tabular}

\section{Alloy Manufacture}

Commercially pure raw materials for DD6 alloy were used for experimental study and commercial applications. The master alloy heat of DD6 was melted in a vacuum induction furnace according to the process set down by many experiments. The test bars, slabs and blades of DD6 alloy were cast in a directional solidified vacuum furnace.

\section{Microstructure and Heat Treatment}

The heat treatment regime for DD6 alloy was carefully studied to provide acceptable microstructure and optimal mechanical properties. The test results show that DD6 provides attractive solution heat treatment capability. The alloy provides a $20^{\circ} \mathrm{C}$ heat treatment window (numerical difference in ${ }^{\circ} \mathrm{C}$ between the $\gamma^{\prime}$ solvus and incipient melting point) and is thereby able to be fully solutioned. The heat treatment regime of DD6 alloy consists of a three-step process employing solution, primary aging and secondary aging heat treatments. The solution heat treatment, a $1315^{\circ} \mathrm{C}$ for 4 hours cycle, dissolves the coarse as-cast $\gamma^{\prime}$ and eutectic $\gamma-\gamma^{\prime}$ present in the alloy for reprecipitation into more useful fine $\gamma^{\prime}$. Following the solution heat treatment cycle, the primary aging treatment, a $1120^{\circ} \mathrm{C}$ for 4 hours cycle, is used to bond the coating to the alloy, as well as to produce an optimum $\gamma^{\prime}$ size and distribution, and the secondary aging treatment is performed at $870^{\circ} \mathrm{C}$ for 32 hours to precipitate ultra fine $\gamma^{\prime}$ between the larger particles.
The microstructures of DD6 alloy in the as-cast, as-solutioned and fully heat treated conditions are shown in Figure 1. The fully heat treated microstructure of DD6 alloy consists of approximately 65 vol. \% of cuboidal $\gamma^{\prime}$ precipitates in $\gamma$ matrix, and the average width of $\gamma^{\prime}$ is about $0.4 \mu \mathrm{m}$.

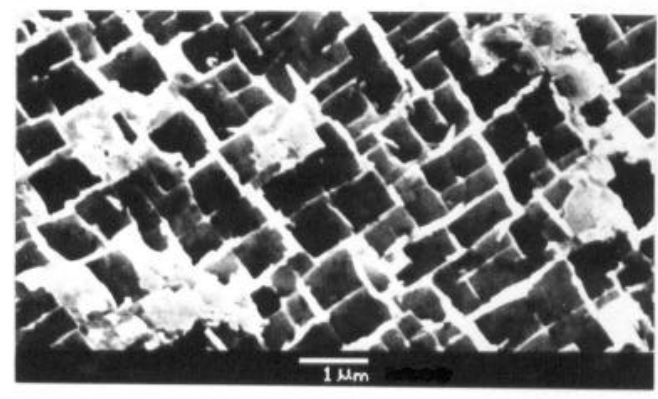

(a) As-cast.

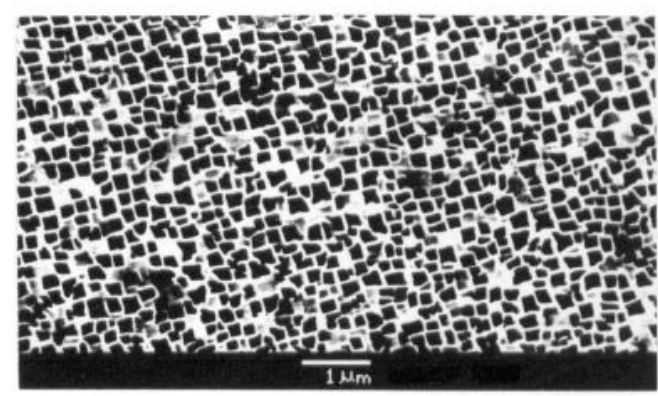

(b) $1315^{\circ} \mathrm{C} / 4 \mathrm{Hrs} / \mathrm{AC}$.

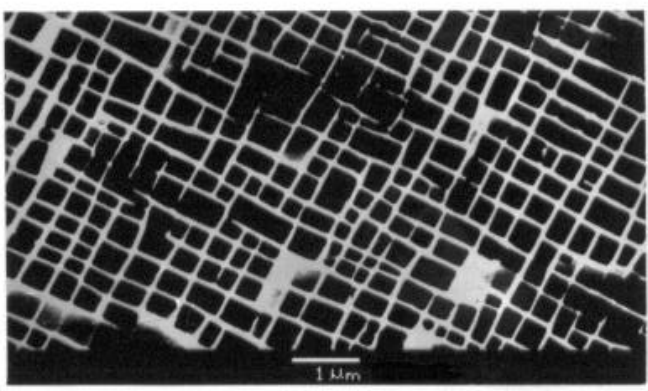

(c) $1315^{\circ} \mathrm{C} / 4 \mathrm{Hrs} . / \mathrm{AC} .+1120^{\circ} \mathrm{C} / 4 \mathrm{Hrs} . / \mathrm{AC},+870^{\circ} \mathrm{C} / 32 \mathrm{Hrs} . / \mathrm{AC}$.

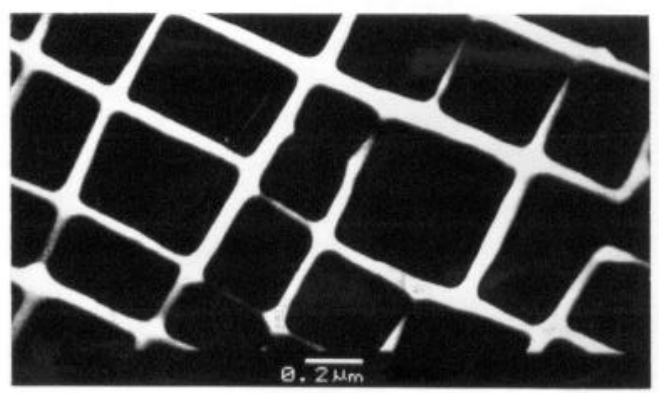

(d) $1315^{\circ} \mathrm{C} / 4 \mathrm{Hrs} / \mathrm{AC} .+1120^{\circ} \mathrm{C} / 4 \mathrm{Hrs} . / \mathrm{AC} .+870^{\circ} \mathrm{C} / 32 \mathrm{Hrs} . / \mathrm{AC}$.

Figure 1: Microstructures of DD6 alloy in the (a) as-cast, (b) assolutioned, (c) and (d) fully heat treated. 


\section{Microstructural Stability}

The microstructural stability at temperatures above $1000^{\circ} \mathrm{C}$ was a key concern in the development of DD6 alloy. TCP phase formation is typically observed in many single crystal superalloys, especially those containing $\mathrm{Re}$, although a small amount of TCP is not considered detrimental to creep rupture and other properties ${ }^{[19]}$. DD6 alloy exposed at $1093^{\circ} \mathrm{C}$ for 1000 hours shows no TCP phases formation and the microstructure of the alloy possesses good stability. The microstructural stability of DD6 is maintained by the reduction of chromium content and the increase of cobalt content. It can be found from Figure 2 that coarsening and rafting of $\gamma^{\prime}$ precipitates occurred in the exposed specimens of DD6 alloy.

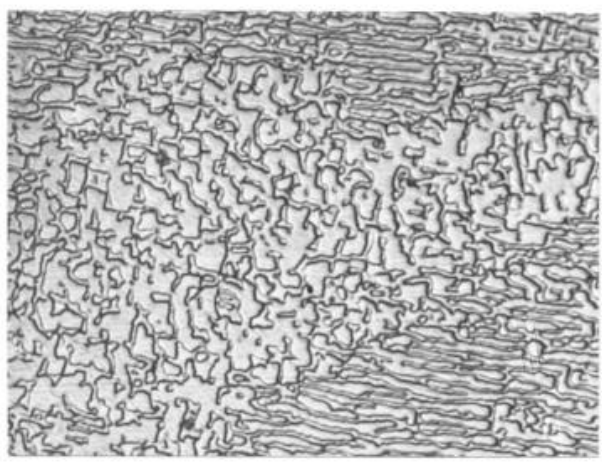

Figure 2: Microstructure of DD6 exposed at $1093^{\circ} \mathrm{C}$ for 1000 hours.

\section{Mechanical Properties}

\section{Tensile Properties}

The tensile properties of DD6 have been extensively characterized in a series of tests between room temperature and $1070^{\circ} \mathrm{C}$ and are shown in Figure 3. It can be seen that the

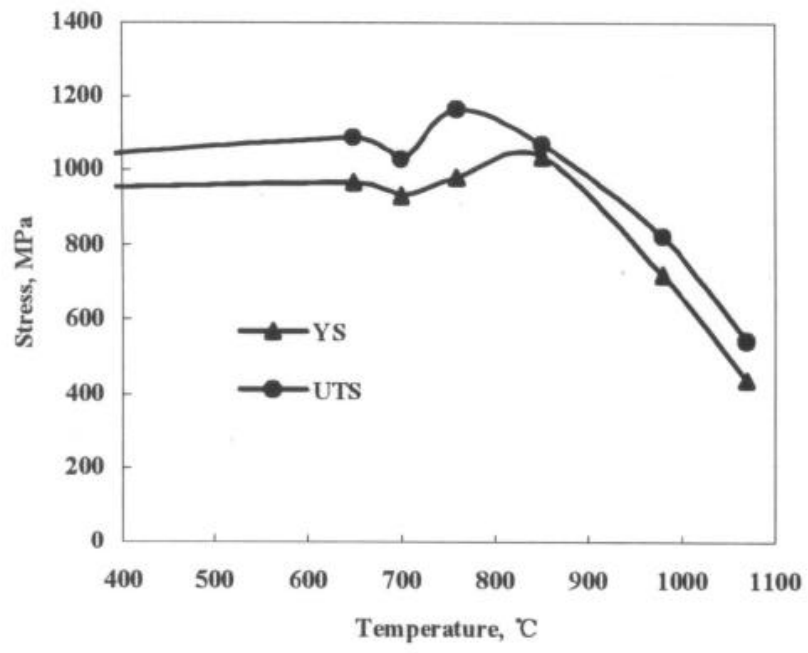

Figure 3: Yield strength and ultimate tensile strength of DD6. ultimate tensile strength and yield strength of DD6 alloy peaks at about $760^{\circ} \mathrm{C}$ and $850^{\circ} \mathrm{C}$ respectively, while relatively good ductility is maintained throughout the tested regime from room temperature to $1070^{\circ} \mathrm{C}$. The ultimate tensile strength and yield strength of DD6 at $760^{\circ} \mathrm{C}$ are approximately $1164 \mathrm{MPa}$ and $981 \mathrm{MPa}$, respectively. Table III shows a comparison of the yield strength of DD6 alloy with other single crystal superalloys. The yield strength of DD6 at room temperature is equivalent to that of the first generation single crystal DD3, while DD6 offers an improvement compared with that of DD3 at middle and high temperatures. The yield strengths of DD6 alloy at $20^{\circ} \mathrm{C}, 650^{\circ} \mathrm{C}$ and $980^{\circ} \mathrm{C}$ are similar to those of other second generation single crystal alloys.

Table III Yield strength of DD6 alloy and other single crystal superalloys ${ }^{[11,14,25,26]}$

\begin{tabular}{|c|c|c|c|c|c|}
\hline \multirow{2}{*}{ Alloy } & \multicolumn{5}{|c|}{ Yield strength, MPa } \\
\cline { 2 - 6 } & $20^{\circ} \mathrm{C}$ & $650^{\circ} \mathrm{C}$ & $850^{\circ} \mathrm{C}$ & $871^{\circ} \mathrm{C}$ & $980^{\circ} \mathrm{C}$ \\
\hline PWA1484 & & 965 & & & \\
\hline CMSX-4 & 971 & 947 & & 899 & 704 \\
\hline DD3 & 927 & & 862 & & 523 \\
\hline DD6 & 929 & 965 & 1035 & & 721 \\
\hline
\end{tabular}

\section{Creep Rupture Properties}

The creep rupture properties of DD6 alloy were studied from 650 ${ }^{\circ} \mathrm{C}$ to $1100{ }^{\circ} \mathrm{C}$. The creep rupture lives of DD6 alloy at the conditions of $982^{\circ} \mathrm{C} / 248.2 \mathrm{MPa}, \quad 1070^{\circ} \mathrm{C} / 160 \mathrm{MPa}, \quad 1093{ }^{\circ} \mathrm{C}$ $/ 124 \mathrm{MPa}$ and $1100^{\circ} \mathrm{C} / 140 \mathrm{MPa}$ are about 307 hours, 178 hours, 484 hours and 148 hours, respectively. The creep rupture properties are summarized in Figure 4 showing a Larson Miller Parameter comparison between DD6 and DD3. Figure 5 illustrates the $0.2 \%$ creep strength of DD6 and DD3 at $850^{\circ} \mathrm{C}$. The second generation single crystal alloys generally exhibit enhanced creep strength relative to the first generation single crystal alloys. DD6 alloy possesses greater creep strength than DD3 alloy from

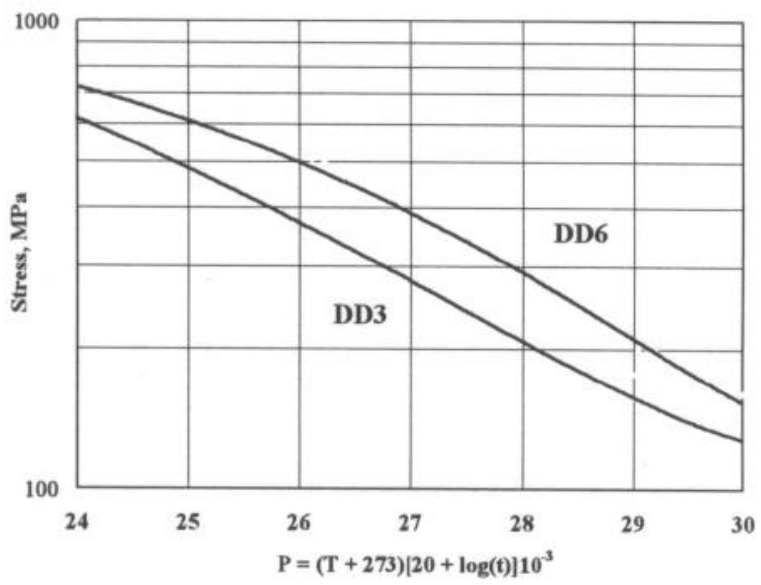

Figure 4: Larson-Miller creep strength of DD6 and DD $3^{[26]}$. 


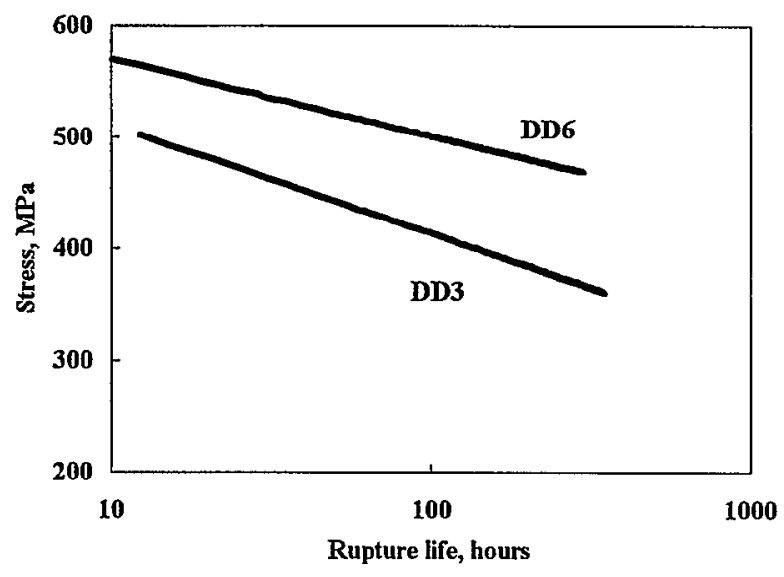

Figure 5: $850^{\circ} \mathrm{C} \quad 0.2 \%$ creep strength of DD6 and $\mathrm{DD}^{[26]}$.

$760^{\circ} \mathrm{C}$ to $1100^{\circ} \mathrm{C}$. The relative improvement depends upon the alloy systems compared, the advantage of DD6 alloy in temperature capability is about $40^{\circ} \mathrm{C}$ relative to DD3 alloy. The $40^{\circ} \mathrm{C}$ advantage over DD3 alloy is maintained even at the higher temperatures and longer times due to the good microstructural stability of DD6 alloy. The high creep rupture properties of DD6 alloy are mainly attributable to the refractory element contents.

The creep rupture lives of DD6 and other second generation single crystal superalloys at $982{ }^{\circ} \mathrm{C} / 248.2 \mathrm{MPa}$ and $1093{ }^{\circ} \mathrm{C}$ 1124MPa are shown in Figure 6 and Figure 7, respectively. The creep strengths of DD6 alloy are at least equivalent to those of other second generation single crystal superalloys widely used in the world, such as CMSX -4 , Rene' 15 and SC180, even better in certain tests.

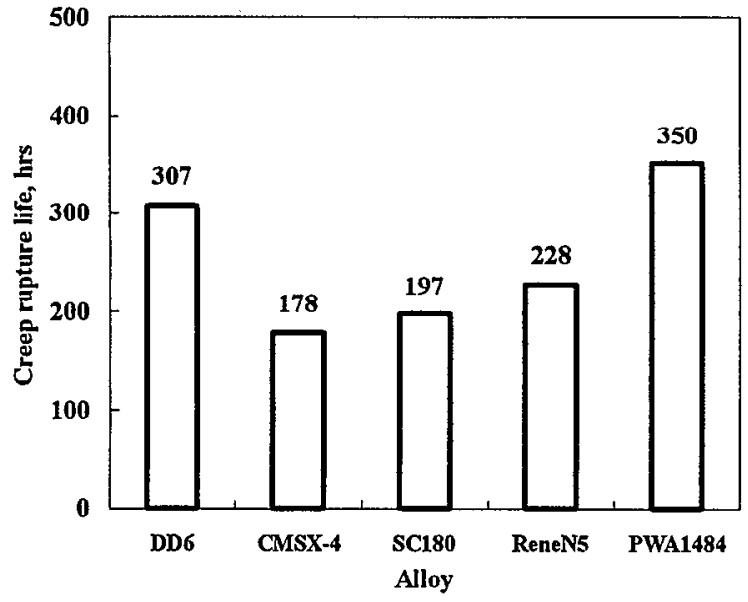

Figure 6: Creep rupture lives of DD6 and other second generation single crystal superalloys at $982^{\circ} \mathrm{C} / 248.2 \mathrm{MPa}^{[1] .13-15]}$.

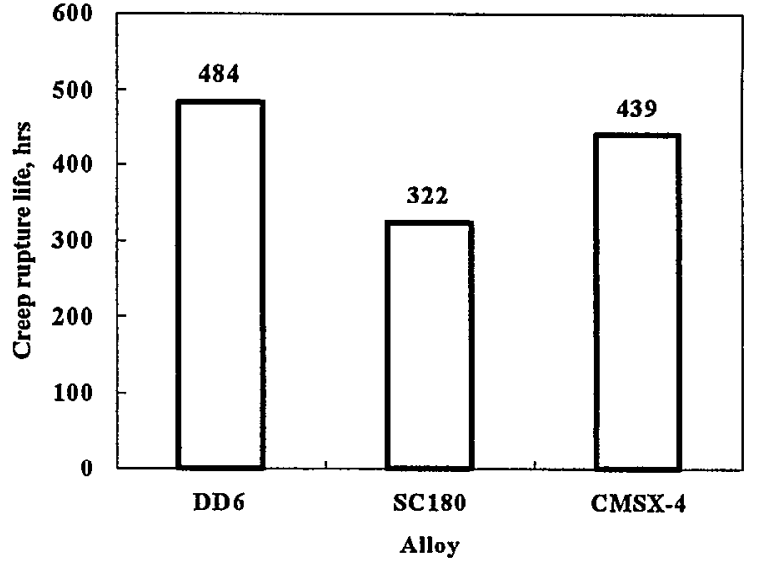

Figure 7: Creep rupture lives of DD6 and other second generation single crystal superalloys at $1093^{\circ} \mathrm{C} / 124 \mathrm{MPa}^{[14,15]}$.

\section{Fatigue}

High cycle fatigue tests have been performed for DD6 alloy. The advantage shown in the creep rupture properties over DD3 generally hold for the fatigue properties. The smooth high cycle fatigue life of DD6 at $700^{\circ} \mathrm{C}$ in the uncoated condition is shown in Figure 8. For $10^{7}$ cycle smooth high cycle fatigue (HCF), DD6 alloy provides a $20 \mathrm{MPa}$ advantage relative to $\mathrm{DD} 3$ alloy at $700^{\circ} \mathrm{C}$ in the uncoated condition. DD6 alloy exhibits excellent HCF capability overall especially at higher temperatures (between 800 $950^{\circ} \mathrm{C}$ ). The low cycle fatigue properties for DD6 alloy are being studied.

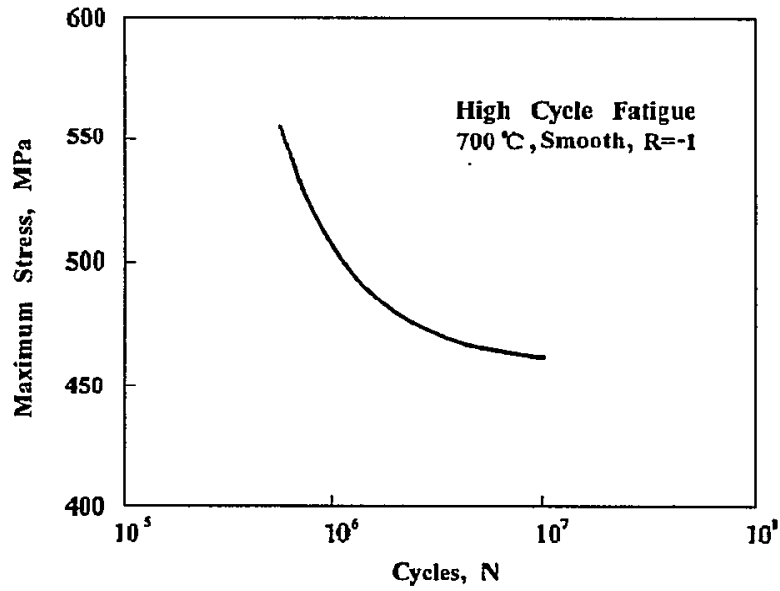

Figure 8: High cycle fatigue of DD6 at $700^{\circ} \mathrm{C}$ in uncoated condition. 


\section{Environmental Properties}

Environmental tests performed on superalloys often give rise to varied results, depending on methods employed. Tests of the environmental resistance of DD6 alloy were undertaken by both burner rig and crucible (static) evaluation methods. The tests of the oxidation resistance of DD6 alloy were performed at $1000^{\circ} \mathrm{C}$ and $1100^{\circ} \mathrm{C}$. Weight change rates of the oxidation resistance tests of DD6 and DD3 alloy at $1100^{\circ} \mathrm{C}$ for 100 hours, in the uncoated conditions by the crucible method, are shown in Figure $9^{[16,26]}$. The oxidation resistance of DD3 alloy is low, while DD6 alloy exhibits very good oxidation resistance for the duration of the test, ie., 100 hours, which is about 4-6 times improvement relative to DD3. The excellent oxidation resistance of DD6 is attributable to its Ta content compared to DD3 that contains no Ta, and the fact that it contains no $\mathrm{Ti}$, despite the $\mathrm{Cr}$ level of DD6 being $50 \%$ lower than DD3.

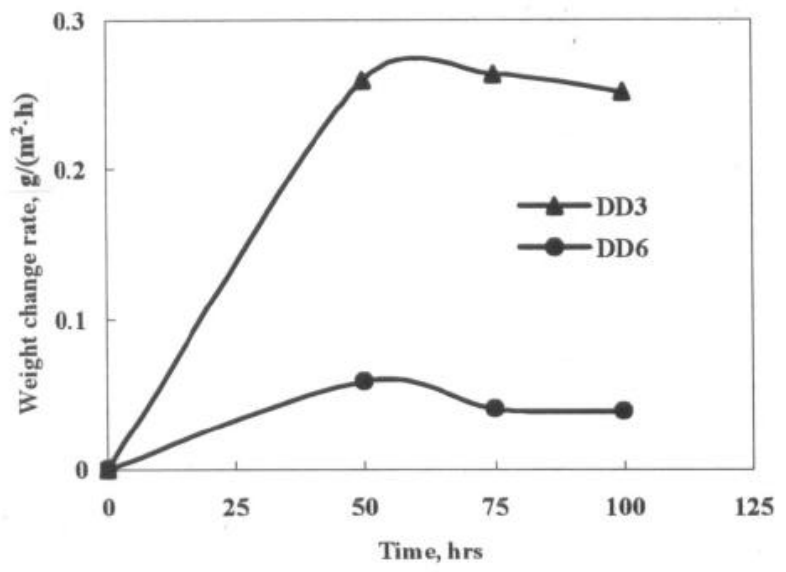

Figure 9: Oxidation resistance properties of DD6 and DD3 at $1100^{\circ} \mathrm{C}$ on uncoated specimens by crucible method ${ }^{[16,26]}$.

Table IV lists the hot corrosion resistance properties of DD6 and DD3 alloy at $900^{\circ} \mathrm{C}$ for tested 100 hours in uncoated conditions by the burner rig method ${ }^{[16,26]}$. The actual test results are presented in terms of the weight change rates of the specimen. In this table, the salt content in the hot corrosion resistance test for DD6 is $0.002 \%$ while that of DD3 is $0.0005 \%$, but the weight change rate of DD6 is 10 times improvement compared to DD3. The specimen appearances tested for the hot corrosion resistance of DD6 and DD3 at $900^{\circ} \mathrm{C}$ for 100 hours, in uncoated conditions at $0.002 \%$ salt content by burner rig method, are shown in Figure 10 .

Table IV Hot corrosion resistance of DD6 and DD3 at $900^{\circ} \mathrm{C}$ for 100 hours ${ }^{[16,26}$

\begin{tabular}{|c|c|c|}
\hline Alloy & DD6 & DD3 \\
\hline Weight change rate, $\mathrm{g} /\left(\mathrm{m}^{2} \cdot \mathrm{h}\right)$ & 0.053 & 0.595 \\
\hline
\end{tabular}

* The salt content in the hot corrosion resistance test of DD6 is $0.002 \%$, while that of DD3 is $0.0005 \%$.
Therefore, DD6 alloy provides surprisingly good oxidation characteristics, as confirmed through both burner rig and crucible tests. At the same time, similar multiple source testing confirms that DD6 exhibits excellent hot corrosion capabilities.

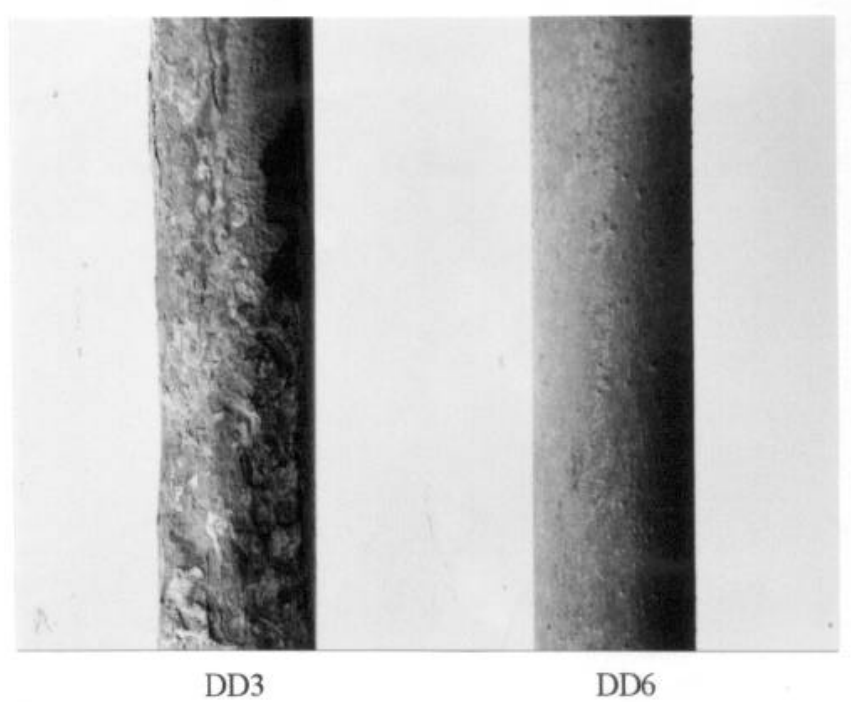

Figure 10: Appearances of the specimens of the hot corrosion resistance for DD6 and DD3 tested by burner rig method at $900^{\circ} \mathrm{C}$ for 100 hours, in uncoated condition at $0.002 \%$ salt content.

The MCrAIX coating was applied to DD6 alloy successfully. For a $10^{7}$ cycle at $700^{\circ} \mathrm{C}$, the smooth high cycle fatigue life of DD6 alloy with MCrAIX coating is approximately equal to that of the alloy in uncoated condition. The applications of environmental coating may further improve the oxidation and hot corrosion resistance of DD6 alloy.

\section{Castability}

Casting trials have been conducted on DD6 alloy involving a great number of test bars, test slabs and some complex shaped hollow turbine blades. The results of the detailed inspections for the crystal quality and casting yields obtained in these trials demonstrate that DD6 possesses excellent castability.

The castability of DD6 alloy is enhanced by alloy design. It is considered that addition of $\mathrm{Ta}$ in alloy has beneficial effect on single crystal casting process in reducing alloy freckle formation $^{[21]}$. Thus significant Ta element is employed to DD6 alloy and the Ta:W ratio was regulated for beneficial effects.

\section{Summary}

A low-cost second generation single crystal superalloy, designated DD6, has been developed. With the help of computer aided design alloy composition, the contents of tungsten, molybdenum, tantalum and rhenium were judiciously balanced with the predominating rhenium requirement. The alloy contains 2 wt. $\%$ of Re, only $2 / 3$ of other second generation single crystal 
superalloys, such as PWA1484, CMSX-4 and Rene'N5. Therefore, a significant cost reduction for DD6 alloy is expected.

DD6 alloy has an approximate $40^{\circ} \mathrm{C}$ improvement of creep strength relative to the first generation single crystal alloy DD3. The tensile properties, creep rupture properties of DD6 alloy are comparable to those of other second generation single crystal superalloys used in commercial applications. DD6 alloy also provides excellent oxidation resistance and hot corrosion resistance. In addition, the microstructural stability of DD6 at elevated temperature after long term exposure is maintained. DD6 alloy also has satisfactory heat treatment characteristics, good single crystal castability and coatability.

\section{Beferences}

1. M. Gell, D. N. Duhl and A. F. Giamei, "The Development of Single Crystal Superalloy Turbine Blades," Superalloys 1980, (Warrendale, PA: TMS, 1980), 205-214.

2. J. W. Holmes and K. S. O'Hara, ASTM STP 942, (Philadelphia, PA: ASTM, 1988), 672-691.

3. D. A. Ford and R. P. Arthey, "Development of Single Crystal Alloys for Specific Engine Application," Superalloys 1984, ed. M. Gell et al., (Warrendale, PA: TMS, 1984), 115124.

4. E. Bachelet and G. Lamanthe, (Paper Presented at the National Symposium on SX Superalloys, Viallard-de-Lans, France, 26-28 February 1986).

5. T. Khan and M. Brun, (Paper Presented at the Symposium on SX Alloys, Munich, Germany, MTU/SMCT, June 1989).

6. K. Harris and G. L. Erickson, Cannon-Muskegon Corporation, U. S. patient 4,582,548-CMSX-2 Alloy.

7. K. Harris and G. L. Erickson, Cannon-Muskegon Corporation, U. S. patient 4,721,540-CMSX-6 Alloy.

8. G. L. Erickson, Cannon-Muskegon Corporation, U. S. patient 5,489,346-CMSX-11B Alloy.

9. G. L. Erickson, "The Development of the CMSX-11B and CMSX-11C Alloys for Industrial Gas Turbine Application," Superalloys 1996, ed. R. D. Kissing et al., (Warrendale, PA: TMS, 1996), 45-52

10. Wu Zhongtang, Wen Zhongyuan and Chen Dehou, "Composition Design and Experimental Study of Single Crystal Alloy DD3," Acta Metallurgica Sinica, 23(4) (1987), B171-B178.

11. A. D. Cetel and D. N. Duhl, "Second Generation NickelBase Single Crystal Superalloy," Superalloys 1988, ed. S. Reichman et al., (Warrendale, PA: TMS, 1988), 235-244.

12. D. N. Duhl and A. D. Cetel, United Technologies Corporation, U. S. patient 4,719,080- PWA1484 Alloy.

13. C. S. Wukusick and L. Buchakjian, U. K. Patent Appl. GB2235697, "Improved Property Balanced Nickel-base Superalloys for Producing Single Crystal Articles"-Rene' N5 Alloy.

14. K. Harris and G. L. Erickson, Cannon-Muskegon Corporation, U. S. patient 4,643,782-CMSX-4 Alloy.

15. X. Nguyen-Dinh, Allied-Signal, Inc., U. S. patent
4,935,072-SC 180 Alloy.

16. Li Jiarong, Zhong Zhengang, Tang Dingzhong et al., "Low Cost Second Generation Single Crystal Superalloy DD6," Acta Metallurgica Sinica, 35(Suppl.2) (1999), S266-S269.

17. W. S. Walston, E. W. Ross, T. M. Pollock and K. S. O'Hara, General Electric Company, U. S. patent 5,455,120-Rene' N6 Alloy

18. W. S. Walston, E. W. Ross, K. S. O'Hara and T. M. Pollock, General Electric Company, U. S. patent 5,270,123-Rene' N6 Alloy.

19. W. S. Walston, K. S. O'Hara, E. W. Ross, T. M. Pollock and W. H. Murphy, "Rene'N6: Third Generation Single Crystal Superalloy," Superalloys 1996, ed. R. D. Kissinger et al., (Warrendale, PA: TMS, 1996), 27-34.

20. G.L.Erickson, Cannon-Muskegon Corporation, U.S. patent 5,366,695-CMSX-10 Alloy.

21. G.L.Erickson, "The Development and Application of CMSX-10," Superalloys 1996, ed. R. D. Kissinger et al., (Warrendale, PA: TMS, 1996), 3544.

22. Jiarong $\mathrm{Li}$, Dingzhong Tang, Riling Lao et al., "Effects of Rhenium on Creep Rupture Life of a Single Crystal Superalloy," Journal of Materials Science and Technology, 15(1) (1999), 53-57.

23. K. Matsugi, Y. Murata and M. Morinaga, "An Electronic Approach to Alloy Design and Its Application to NickelBased Single Crystal Superalloys," Materials Science and Engineering, 172A(1993), 101-110.

24. R. G. Barrows and J. B. Newkirk, "A Modified System for Predicting $\sigma$ Formation," Metallurgical Transactions, 3(11) (1972), 2889-2893.

25. A.Sengupta, S.K.Putatunda, L.Bartosiewicz et al., "Tensile Behavior of a New Single Crystal Nickel-Based Superalloy (CMSX-4) at Room and Elevated Temperatures," Joumal of Materials Engineering and Performance, 3(5) (1994), 664672.

26. Wu Zhongtang, "DD3 alloy," Chines Aeronautical Materials Handbook, vol. 2, ed. Yan Minggao, (Beijing, China Standard Press, 1989), 868-881. 